\title{
BIOEQUIVALENCE STUDY OF ANTIDIABETIC ACTIVITY BETWEEN TWO MARKETED FORMULATIONS OF METFORMIN ON GLUCOCORTICOID-INDUCED HYPERGLYCEMIA IN RABBIT
}

\author{
DEBANGA DAS*, JASHABIR CHAKRABORTY, SUVAKANTA DASH \\ Girijananda Chowdhury Institute of Pharmaceutical Science (GIPS), Azara, Guwahati, Assam 781017 \\ Email: das.debanga.dd@gmail.com
}

Received: 28 Jan 2017, Revised and Accepted: 20 Apr 2017

\begin{abstract}
Objective: Bioequivalence studies are the commonly accepted methods displaying therapeutic equivalence between two products. This study was conducted to evaluate the bioequivalence study of anti-diabetic activity between two formulations of metformin tablets which were marketed in India.

Methods: In in vitro study five essential in vitro tests including disintegration, weight variation, hardness, friability and a comparative in vitro dissolution study were performed.

Results: For in vivo study adult male rabbits were divided into three groups of two each. The first group is regarded as control group received $3 \mathrm{ml}$ of normal saline daily by using the gastric tube for $15 \mathrm{~d}$ and the second and third group received $(0.35 \mathrm{mg} / \mathrm{Kg} \mathrm{B} . \mathrm{W}$. single dosage) of dexamethasone tablets which were powdered, dissolved in $3 \mathrm{ml}$ of normal saline daily for $15 \mathrm{~d}$. After $15 \mathrm{~d}$ the blood glucose of second and third group was estimated and after that received formulation $\mathrm{X}$ and formulation $\mathrm{Y}$, dissolved in $3 \mathrm{ml}$ of normal saline daily for $15 \mathrm{~d}$ at the dose of 0.5 gm/kg body weight orally. After $15 \mathrm{~d}$ again blood glucose of second and third group was estimated and compare the results of both the group. This shows the favourable response of metformin against glucocorticoid-induced renal damage and hyperglycemia.
\end{abstract}

Conclusion: Results of this study showed that the extent, rate of absorption and anti-diabetic activity of two different formulations of metformin tablets are bioequivalent to each other.

Keywords: Bioequivalence, Hyperglycemia, Dexamethasone, Metformin

(c) 2017 The Authors. Published by Innovare Academic Sciences Pvt Ltd. This is an open access article under the CC BY license (http://creativecommons.org/licenses/by/4.0/) DOI: http://dx.doi.org/10.22159/ijcpr.2017v9i4.20762

\section{INTRODUCTION}

Bioequivalence is defined as the absence of a significant difference in the rate and extent to which the active ingredient or active moiety in pharmaceutical equivalents or pharmaceutical alternatives becomes available at the site of drug action when administered at the same molar dose under similar conditions in an appropriately designed study [1].

Diabetes mellitus is a disorder of carbohydrate, fat and protein metabolism, which is characterized by an absolute or relative lack of insulin, resulting in hyperglycemia. It is mainly of two types: type 1 diabetes mellitus and type 2 diabetes mellitus [2]. Type- 1 diabetes requires insulin treatment, whereas Type-2 diabetes, which is characterized by insulin resistance, can be treated using a variety of therapeutic approaches. Hyperglycemia is thought to be a primary factor in the onset of diabetes, although hyperlipidemia also plays a role. The major organs active in the regulation of blood glucose are the pancreas, liver, skeletal muscle, adipose tissue, intestine, and kidney [3]. Long-term diabetes mellitus leads to a variety of complications such as cardiovascular disease, retinopathy, nephropathy and neuropathy. This disease remains to be an expanding global health crisis because it is a potentially morbid condition with high prevalence worldwide thus it constitutes a major health concern. World health organisation (WHO) estimates that by 2030 there will be 333 million diabetics in the world, about 50.8 million in India, 11 million in Brazil, and 26 million people in U. S population [4].

In this project, I select glucocorticoid-induced model because the lack of quality studies is done in glucocorticoid in diabetes mellitus profile in the rabbit. So I chose a glucocorticoid-induced model to know the effect of glucocorticoid in the rabbit. Glucocorticoids oppose insulin action and stimulate gluconeogenesis, especially in the liver, resulting in a net increase in hepatic glucose output and induce insulin resistance and hyperglycemia. Although glucocorticoids can counteract several effects of insulin, such as reduction of appetite at a central level, the main mechanisms that lead to the onset of hyperglycemia include an increase in insulin resistance with increased glucose production and inhibition of the production and secretion of insulin by pancreatic $\beta$-cells [5]. I select metformin as anti-diabetic drug because metformin is the most commonly used drug in the treatment of diabetes mellitus and the cost is less. Metformin acts by decreasing intestinal absorption of glucose, reducing hepatic glucose production and increasing insulin sensitivity. Metformin is considered as the drug in the treatment of type 2 diabetes mellitus [6].

\section{MATERIALS AND METHODS}

Tablet evaluation test

\section{Medical drug}

Two different formulations of Metformin $\mathrm{HCl} 500 \mathrm{mg}$ and one formulation of dexamethasone were purchased from a registered pharmacy at Guwahati. The study was performed within product expiration dates. The reagents used were potassium dihydrogen phosphate orthophosphate and sodium hydroxide.

\section{Equipment}

USP II (Paddle Type) dissolution test apparatus, UV Spectrophotometer, Electronic Analytical Balance, Digital tablet disintegration test apparatus, Hardness Tester, Friability Tester were used for the analysis.

\section{Uniformity of weight}

Sample tablets (20) of each formulation were weighed together and average weight was determined. Each tablet was weighed individually on an analytical balance and the percentage (\%) deviation was determined [7].

\section{Hardness test and thickness of the tablets}

Randomly selected 10 tablets were placed between the jaws of the hardness tester individually. The thickness of tablets from each 
brand was also measured by the same apparatus. After inserting the approximate thickness values of the tablets, the accurate values of those parameters were measured. The pressure at which each tablet crushed was recorded according to IP 2014 specifications. The average crushing strength/hardness values were reported in Newton (N) [7].

\section{Friability test}

Twenty tablets of each brand were weighed and subjected to abrasion using a Roche friabilator at 100 revolutions for $4 \mathrm{~min}$. The tablets were dedusted and weighed again then the percent of weight loss was recorded. The friability of the tablets was then calculated using the following expression [6].

$\%$ Friability $=[($ Initial weight - Final weight $) /$ Initial weight $] \times 100$

\section{Disintegration test}

The disintegration time of randomly selected six tablets of each sample was determined at $37 \pm 20{ }^{\circ} \mathrm{C}$ in distilled water using disintegration apparatus, according to IP specifications. The machine was set to $30 \mathrm{rpm}$. The disintegration time was taken to be the time no granule of any tablet was left in the mesh [7].

\section{Uniformity content of metformin hydrochloride}

An U. V. spectrophotometric method based on the measurement of absorbance at $\lambda_{\max } 232 \mathrm{~nm}$ in phosphate buffer of $\mathrm{pH} 6.8$ was used for estimation of Metformin hydrochloride. Before performing dissolution test, ten serially diluted solutions of the reference standard (Metformin hydrochloride) and a standard solution curve drawn. The curve was linear in concentration $2 \mu \mathrm{g} / \mathrm{ml}, 4 \mu \mathrm{g} / \mathrm{ml}$, $6 \mu \mathrm{g} / \mathrm{ml}, 8 \mu \mathrm{g} / \mathrm{ml}, 10 \mu \mathrm{g} / \mathrm{ml}$. Mean peak absorbance was plotted against the concentration to form the calibration curve [8].

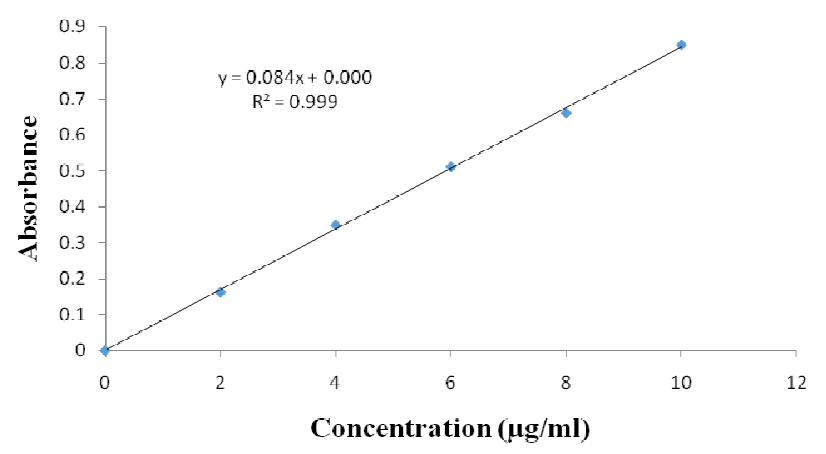

Fig. 1: Calibration curve of metformin hydrochloride

\section{Dissolution test for in vitro bioequivalence study}

The dissolution rate of Metformin $\mathrm{HCl}$ tablet was studied using USP II (Paddle type) digital tablet dissolution test apparatus employing a paddle stirrer at $100 \mathrm{rpm}$ using $900 \mathrm{ml}$ of $\mathrm{pH} 6.8$ potassium dihydrogen phosphate orthophosphate buffer at $(37.0 \pm 0.5){ }^{\circ} \mathrm{C}$ as dissolution medium. One tablet (500 $\mathrm{mg}$ ) was used in each test. A sample of dissolution fluid $(10 \mathrm{ml})$ was withdrawn at intervals of 5 , $10,15,30,45$ and 60 minutes. A fresh $10 \mathrm{ml}$ dissolution medium was replaced after each sampling to maintain sink condition. Each of the withdrawn samples was filtered and the filtrate diluted. The absorbance of the resultant solution was then determined by UVVisible (Ultra-Violate visible) spectrophotometer at $\lambda_{\max } 232 \mathrm{~nm}$. The concentration was determined against a standard solution of Metformin hydrochloride drug in the same medium. From the concentration, percentage (\%) drug release was determined at specified time interval. The percentage of drug released is calculated using formula [7].

Percentage of drug release $(\%)=[$ Amount of drug released $(\mathrm{mg} / \mathrm{ml}) /$ drug content in label $(\mathrm{mg})] \times 100$

\section{Animal experiment on anti-diabetic activity}

\section{Protocol of work}

\section{Medical drug}

Dexamethasone sod. Phosphate was used ( $0.35 \mathrm{mg} / \mathrm{kg}$, B.W.) for induction of hyperglycemia in rabbits. Two formulations of metformin (formulation $\mathrm{X}$ and formulation $\mathrm{Y}$ ) was used as an antidiabetic drug.

\section{Experimental animals}

Six healthy adult male rabbits were brought from the animal house GIPS, body weight (1500-2000) gm. were used in the study.

\section{Equipment}

The one-touch simple select blood glucose monitoring system (Flextronics Industrial Co, Ltd) is used for determination blood glucose.

\section{Experimental design}

The normal blood glucose levels of all rabbits were estimated before giving drugs. The first group had been regarded as control each rabbit in the control group was drenched $3 \mathrm{ml}$ of normal saline daily by using the gastric tube for $15 \mathrm{~d}$. The second and third group dexamethasone was drenched $(0.35 \mathrm{mg} / \mathrm{Kg}$ B.W. single dosage $)$ of dexamethasone tablets which were powdered, dissolved in $3 \mathrm{ml}$ of normal saline solution intravenously in the marginal ear vein to induce hyperglycemia daily for 15 days. After $15 \mathrm{~d}$ the blood glucose levels of all rabbits were determined by using a glucometer. The second and third group was drenched $(0.5 \mathrm{~g} / \mathrm{Kg}$ B.W. single dosage) of formulation $\mathrm{X}$ and formulation $\mathrm{Y}$ dissolved in $3 \mathrm{ml}$ of normal saline daily for $15 \mathrm{~d}$. After $15 \mathrm{~d}$ again the blood glucose levels of all groups were determined and compare the blood glucose levels of each group [9].

\section{RESULTS}

\section{Tablet evaluation test}

\section{Physiochemical properties of Metformin hydrochloride tablets}

Uniformity of weight, hardness, friability, disintegration time, size and thickness are shown in table 1 . The in vitro percentage drug release of Metformin hydrochloride tablets are shown in table 2. Fig. 2 illustrates the dissolution profile of the tested Metformin hydrochloride tablets of different brands.

Table 1: Evaluated physicochemical parameters of different types of Metformin $\mathrm{HCl}$ tablets

\begin{tabular}{lll}
\hline Parameter & Formulation & Y \\
\cline { 2 - 3 } & $\mathbf{X}$ & 0.30 \\
\hline Thickness (cm) & 0.35 & 1.60 \\
Size (cm) & 1.30 & 0.602 \\
Uniformity of weight & 0.552 & 5.60 \\
Hardness (kg/cm ${ }^{2}$ ) & 7.98 & $5 \mathrm{~min} 25 \mathrm{sec}$ \\
Disintegration Time (min) & $5 \mathrm{~min} 10 \mathrm{sec}$ & 0.115 \\
Friability (\%) & 0.160 & \\
\hline
\end{tabular}


Table 2: In vitro percentage drug released of different formulations of Metformin $\mathrm{HCl}$ tablets

\begin{tabular}{|c|c|c|c|c|c|c|}
\hline \multirow[t]{2}{*}{ Formulation } & \multicolumn{6}{|c|}{ Drug released (\%) } \\
\hline & $5 \mathrm{~min}$ & $10 \mathrm{~min}$ & $15 \mathrm{~min}$ & $30 \mathrm{~min}$ & $45 \mathrm{~min}$ & $60 \mathrm{~min}$ \\
\hline $\mathrm{X}$ & 24.64 & 44.34 & 57.75 & 63.63 & 67.45 & 68.49 \\
\hline Y & 33.55 & 53.83 & 58.26 & 60.02 & 61.30 & 63.40 \\
\hline
\end{tabular}

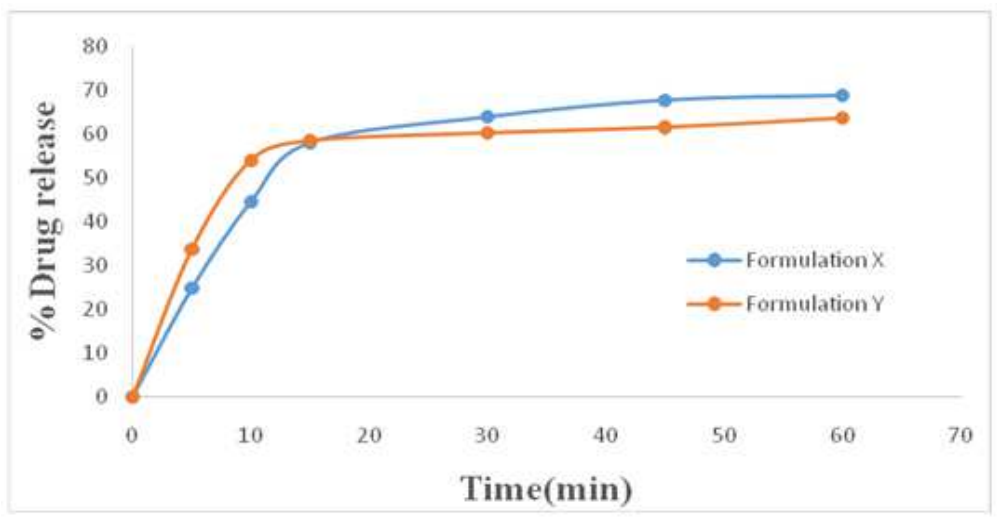

Fig. 2: Dissolution profile of the different formulations of Metformin $\mathrm{HCl}$ tablets

Table 3: Effect of dexamethasone and formulation on body weight of male rabbits

\begin{tabular}{|c|c|c|c|}
\hline Parameters/Treatments & Initial body weight(g) & Final body weight(g) & Body weight gain(g) \\
\hline Control (Normal saline) (First group) & 1725 & 1790 & 65 \\
\hline Dexamethasone (0.35 mg/kg B.W.)(Second group) & 1760 & 1590 & -170 \\
\hline Dexamethasone (0.35 mg/kg B.W.)(Third group) & 1825 & 1695 & -130 \\
\hline Formulation X (Second group) & 1590 & 1575 & -15 \\
\hline Formulation Y (Third group) & 1695 & 1670 & -25 \\
\hline
\end{tabular}

Table 4: Effect of dexamethasone and formulation on glucose profile of male rabbits

\begin{tabular}{lc}
\hline Parameters/Treatments & Glucose (mg/dl) \\
\hline Control (Normal saline)(First group) & 110.14 \\
Dexamethasone (0.35 mg/kg B.W.)(Second group) & 158.63 \\
Dexamethasone (0.35 mg/kg B.W.)(Third group) & 153.87 \\
Formulation X (Second group) & 107.13 \\
Formulation Y (Third group) & 104.34 \\
\hline
\end{tabular}

\section{Animal experiment}

Effect of dexamethasone and formulation on body weight of male rabbits

In the table 3 showed that effects of dexamethasone, formulation $X$ and formulation $Y$ on body weight of male rabbits.

Effect of dexamethasone and formulation on glucose profile of male rabbits

In the table 4 showed that effects of dexamethasone, formulation $\mathrm{X}$ and formulation $\mathrm{Y}$ on glucose profile of male rabbits.

\section{DISCUSSION}

Metformin hydrochloride is a widely prescribed oral anti-diabetic drug and its official in I. P. 2014. Several brands of Metformin tablets are available in the market leading to a confusion of their quality and prices. The objective of the present study is to make a comparative in vitro and in vivo evaluation of two different brands of Metformin hydrochloride which are commercially available in Guwahati, India. They were subjected to a number of quality control tests in order to assess their biopharmaceutical equivalence.

Glucocorticoids in excess inhibit insulin secretion from pancreatic beta-cells, decrease glucose utilization and stimulate glucagon secretion, lipolysis, proteolysis and hepatic glucose production.
Glucocorticoids can modulate the insulin action at both binding sites and post binding sites and cause decreased glucose utilization in muscles. Glucocorticoids also cause insulin resistance by decreasing hepatic glucose utilization and decreasing glycogen synthesis

In the present study, it was found that dexamethasone causes a decrease in body weight and increases glucose levels leading to hyperglycemia. Metformin prevented the rise in glucose, cholesterol and LDL caused by dexamethasone. Further, this also prevented the progressive decrease in HDL and body weight caused by dexamethasone.

\section{CONCLUSION}

The present study demonstrated that the in vitro drug release profile and anti-diabetic activity of both the formulation are approximately similar to each other so both the formulations of metformin are considered as bioequivalent and useful in the management of diabetes.

\section{CONFLICT OF INTERESTS}

Declare none

\section{REFERENCES}

1. Yogesh P, Ankush C, Jeybalan G, Naresh K, Krupal S, Prashant B. Bioavailability: a pharmaceutical importance in new drug development. Res J Pharm Biol Chem Sci 2012;3:45-52. 
2. Saini S, Kumari S, Verma S, Sharma A. A review on different types of animal models for pharmacological evaluation of anti diabetic drugs. Int J Pharm Phytopharm Res 2013;3:2-12.

3. Singh M, Pathak K. Animal models for biological screening of anti-diabetic drugs: an overview. Eur J Exp Biol 2015;5:37-48.

4. Tripathi V, Verma J. Different models used to induce diabetes: a comprehensive review. Int J Pharm Pharm Sci 2014;6:29-32.

5. Perez A, Chaparro S, Saigi I, Lopez M, Minambres I, Huelgas R. Glucocorticoid-induced hyperglycemia. J Diabetes 2014;6:9-20.

6. Elango $\mathrm{P}$, Ramesh $\mathrm{K}$, Shanmuganathan $\mathrm{S}$. A comparative analysis of commercial metformin tablets. Indian J Clin Practice 2014;24:778-83.

7. Hettiarachchi T, Wickramaratne D, Sudeshika S, Niyangoda D, Sakeena M, Herath $\mathrm{H}$. Comparative in vitro evaluation of metformin HCL tablets commercially available in Sri Lanka. Int J Pharm Pharm Sci 2014;7:520-4.

8. Sachan A, Kumar V, Gupta A. Comparative in vitro evaluation of four different brands of metformin $\mathrm{HCl}$ available in India. Scholars Res Library 2016;8:419-24.

9. Muna H, Saeed A. Amelioration effect of methanolic extract of Cyperus rotundus on type 2 diabetes mellitus, thyroid dysfunction and gallstone induce by dexamethasone in male rabbits. Kufa J Veterinary Med Sci 2016;7:102-18.

\section{How to cite this article}

- Debanga Das, Jashabir Chakraborty, Suvakanta Dash. Bioequivalence study of antidiabetic activity between two marketed formulations of metformin on glucocorticoid-induced hyperglycemia in the rabbit. Int J Curr Pharm Res 2017;9(4):47-50. 